\title{
IMP3 and Malignant Melanoma
}

\author{
Mark J. Mentrikoski ${ }^{1}$ and Haodong $\mathrm{Xu}^{2}$ \\ ${ }^{1}$ Department of Pathology, University of Virginia Health System, \\ Charlottesville, Virginia, \\ ${ }^{2}$ Department of Pathology and Laboratory Medicine, \\ University of Rochester Medical Center, \\ Rochester, New York, \\ USA
}

\section{Introduction}

Malignant melanoma is the deadliest form of skin cancer arising from the abnormal proliferation of epidermal melanocytes. With the incidence and mortality from this disease rising, accurate histopathologic diagnosis is crucial. Most cases of melanoma can be appropriately diagnosed based on morphologic criteria, but a subset of lesions including Spitz and dysplastic nevi, can be difficult to distinguish from malignant proliferations. In addition, even though current immunohistochemical stains tend to be rather sensitive and specific for most types of malignant melanoma (S-100, MelanA/MART-1, HMB-45 and tyrosinase), they are unable to distinguish malignant from benign melanocytes--a potential pitfall in architecturally and cytologically borderline cases, which can lead to inadequate treatment or surveillance. Also, the distinction between intranodal nevi and metastatic melanoma in sentinel lymph nodes is not morphologically straightforward in certain cases; however, the confirmative status of these lymph nodes is very important for clinical outcome and guiding treatment. Thus, finding a method to precisely distinguish melanoma from its benign mimickers is needed. Despite advances in melanoma investigation and research, no reliable diagnostic biomarkers have yet been identified.

Another challenge in melanoma treatment is to determine patients' prognosis. Currently, depth of invasion, tumor ulceration, and status of sentinel lymph node are three common objective measures of prognosis; with invasion greater than $1 \mathrm{~mm}$, ulceration, and lymph node metastases portending a worse outcome. Other features, such as assignment of radial versus vertical growth phase, tumor infiltrating lymphocytes, and Clark's levels, are also useful for prognosis, but tend to be more subjective. Thus, an immunohistochemical marker predictive of disease progression and poorer prognosis would be useful, to identify melanomas with a more aggressive phenotype.

\subsection{IMP3}

Insulin-like growth factor-II (IGF-II) messenger RNA (mRNA)-binding protein-3 (IMP3), also known as $\underline{K}$ homology domain-containing protein overexpressed in cancer (KOC) and L523S, is an mRNA-binding protein which has been considered to play a dual role in 
both embryogenesis and tumor proliferation (Nielsen, Christiansen et al. 1999; Yaniv and Yisraeli 2002). IMP3 is a 580 amino-acid protein encoded by a 4350-bp mRNA transcript produced by a gene located on chromosome 7p11.5 (Mueller-Pillasch, Lacher et al. 1997). As a member of the IGF-II mRNA-binding protein (IMP) family, IMP3 is expressed in first trimester human embryos and term placenta (Yaniv and Yisraeli 2002). By binding downstream transcripts of IGF-II, IMP3 plays a role in early cell growth and proliferation through RNA trafficking and stabilization (Mueller-Pillasch, Pohl et al. 1999; Nielsen, Nielsen et al. 2001). After embryogenesis and development, IMP3 expression is detectable in occasional adult tissues, including the internal root sheath of hair follicles, germinal centers of lymph nodes (Figure 1B), patchy gastrointestinal tract and bronchiolar epithelium (Righi, Zhang et al.; Mueller-Pillasch, Pohl et al. 1999; Nielsen, Christiansen et al. 1999; Hammer, Hansen et al. 2005; Simon, Bourne et al. 2007; Xu, Bourne et al. 2007; Mentrikoski, Ma et al. 2009).

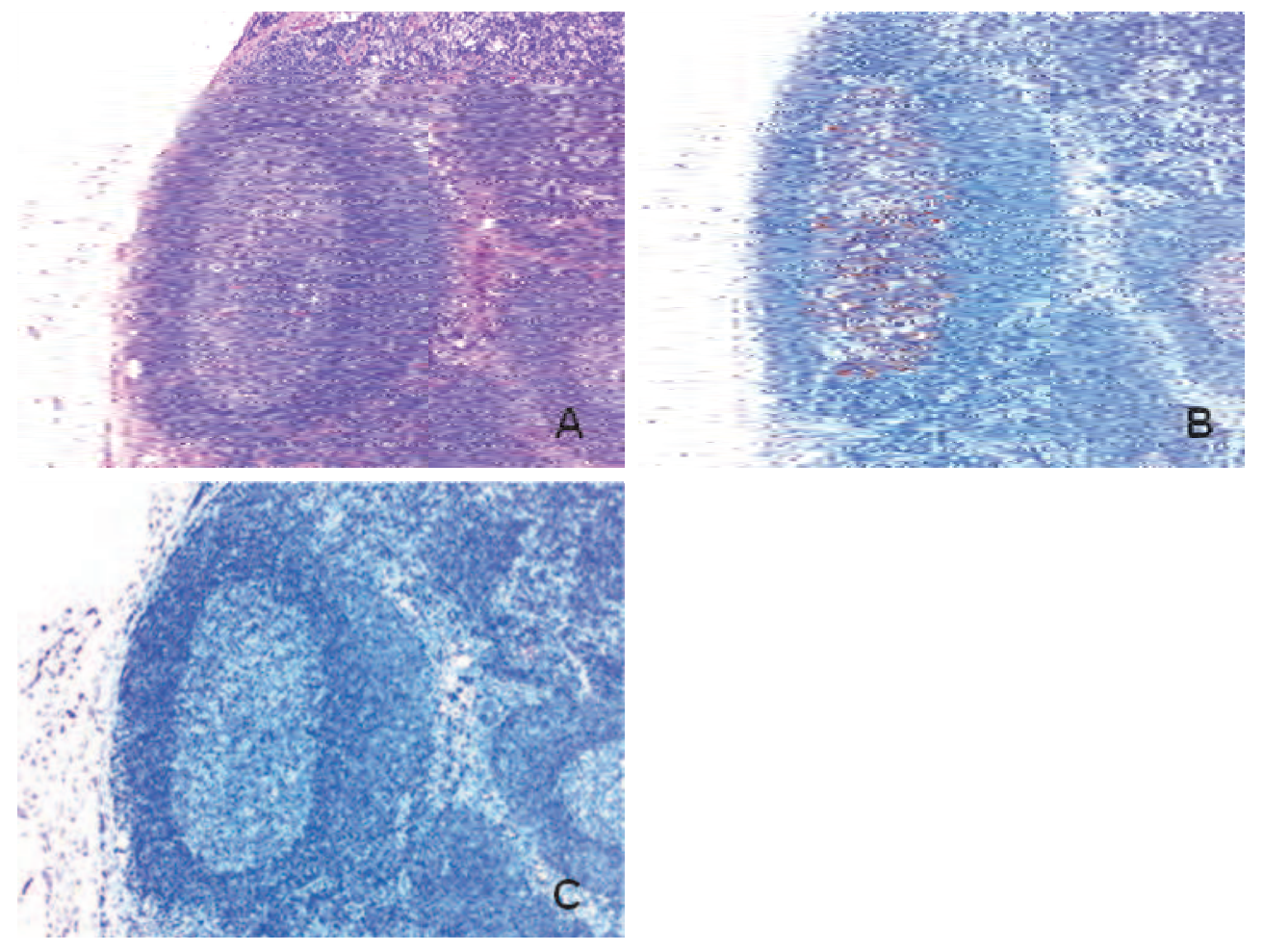

Fig. 1. IMP3 expression in lymph node germinal centers. A: Hematoxylin and Eosin stain shows normal lymph node with germinal center. B: IMP3 staining shows positivity in germinal center lymphocytes. C: Melan-A staining does not highlight any nodal elements. Original magnification is $100 \mathrm{x}$ for $\mathrm{A}, \mathrm{B}$ and $\mathrm{C}$. 
In addition to its expression in fetal development, IMP3 has been detected in numerous malignancies including germ cell carcinomas, renal cell carcinoma, small and non-small cell lung carcinomas, urothelial carcinoma, endometrial serous and cervical carcinomas, Merkel cell carcinoma, extrapulmonary small cell carcinoma, various lymphomas, thyroid carcinoma, mammary breast carcinoma, colonic, gastric and esophageal adenocarcinomas, and osteogenic sarcoma (Asioli, Erickson et al. ; Findeis-Hosey, Yang et al. ; Jin, Seys et al. ; Righi, Zhang et al. ; Wang, Fan et al. 2003; Hammer, Hansen et al. 2005; Jiang 2007; Li, Rock et al. 2007; Simon, Bourne et al. 2007; Do, Kim et al. 2008; Li, Xu et al. 2008; Pryor, Bourne et al. 2008; Zheng, Yi et al. 2008; Jeng, Wang et al. 2009; King, Pasha et al. 2009; Li, Yan et al. 2009; Li, Huang et al. 2009; Lu, Vohra et al. 2009; Mentrikoski, Ma et al. 2009; Pryor, Simon et al. 2009; Slosar, Vohra et al. 2009; Walter, Prasad et al. 2009; Yuan, Wang et al. 2009). Moreover, IMP3 expression has been shown to be a marker of poorer prognosis with decreased overall survival in several tumors including renal cell carcinoma, mammary breast carcinoma, non-small cell lung carcinoma, and numerous gastrointestinal malignancies (Findeis-Hosey, Yang et al. ; Jiang, Chu et al. 2006; Hoffmann, Sheinin et al. 2008; Kobel, Xu et al. 2009; Walter, Prasad et al. 2009). Furthermore, another member of the IMP family of proteins, IMP1, was found to be expressed in primary melanomas, and melanoma cell lines suggesting that these proteins may also play a role in melanoma oncogenesis (Thomas and Erickson 2008).

Although IMP3's precise role in malignant transformation is as yet unknown, it has been shown to promote proper extra-cellular matrix formation, cell adhesion, and tumor invasion (Vikesaa, Hansen et al. 2006; Jeng, Chang et al. 2008), in various cell lines in vitro. These study results, combined with clinicopathologic evidence of a poorer prognosis in tumors with IMP3 overexpression, indicate that regardless of IMP3's exact role in primary oncogenesis, its expression in tumors indicates a more aggressive phenotype. Below we review the identification of IMP3 in cutaneous melanocytic lesions, including malignant melanoma, and discuss its role in the diagnosis and potential prognosis of these lesions.

\section{IMP3 expression in cutaneous melanocytic lesions}

Given IMP3's expression in a plethora of different malignancies, our group hypothesized that IMP3 may be of value in segregating malignant melanoma from benign melanocytic lesions. This was proven to be the case in the original paper by Pryor et al. (Pryor, Bourne et al. 2008). In this study, 56 melanocytic neoplasms, including 11 benign nevi, 8 dysplastic nevi, 10 Spitz nevi, 17 primary melanomas, and 10 metastatic melanomas, were evaluated for IMP3 expression through immunohistochemistry. The results revealed that 23 of 27 melanomas $(85 \%)$ showed moderate-to-strong staining for IMP3, while no benign or dysplastic nevi expressed IMP3. These findings were statistically significant $(P=0.0003)$. Spitz nevi showed weak staining in $30 \%$ of lesions, which was also significantly less than melanoma $(P=0.0215)$ (Pryor, Bourne et al. 2008). Interestingly, when the primary melanomas were subdivided by tumor thickness, IMP3 overexpression was noted to be stronger and more prevalent in tumors with $>1 \mathrm{~mm}$ of invasion, which suggests that IMP3 may be a marker of melanoma progression. In addition, the results also showed that IMP3 is expressed in metastatic melanoma (Figure 2B) significantly more than in thin melanomas. Whether these findings of IMP3 expression are suggestive of a poorer prognosis, is currently being evaluated using long-term outcomes and survival data. 

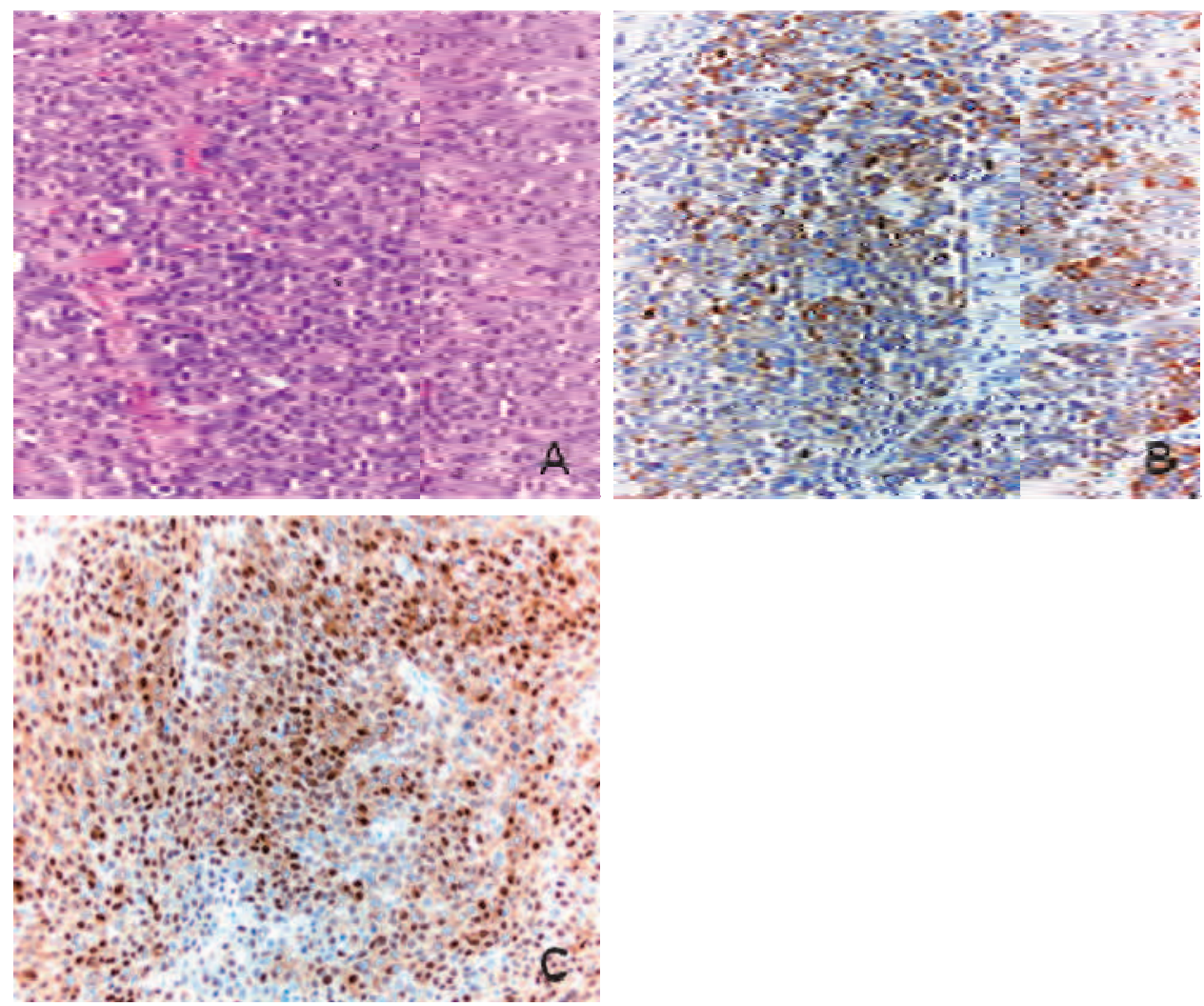

Fig. 2. Metastatic malignant melanoma in soft tissue is strongly and diffusely positive for IMP3. A: Hematoxylin and eosin staining shows metastatic malignant melanoma. B: Strong IMP3 positivity in melanoma cells. C: Strong nuclear immunohistochemical staining for S100 in malignant melanoma. Original magnification is 200x for A, B and C.

A second study examining IMP3 and malignant melanoma was performed by Yu et al., and investigated its expression in atypical Spitz tumors, melanoma in situ (MIS), and desmoplastic melanoma ( $\mathrm{Yu}, \mathrm{Xu}$ et al.). The group confirmed the lack of staining in benign and dysplastic nevi, and only occasional, scattered staining in Spitz nevi. Atypical Spitz nevi showed weak to moderate staining in 7 of 10 cases. Desmoplastic melanoma showed overexpression in 4 of $23(17 \%)$ of cases, similar to results obtained with other melanocytic markers (Busam 2005). In MIS, IMP3 staining was noted as isolated, single cells in $40 \%$ of cases; a similar percentage was observed in superficially invasive melanomas $(<1 \mathrm{~mm})$, but the positive cells had a more prominent, linear arrangement. Although the specificity of IMP3 detection in non-desmoplastic melanomas was less than the original study (50\% vs. $85 \%$, see above), there was nonetheless a significant difference between expression in melanoma compared to benign nevi $(P=0.0251)$. As in the original study, the trend was for deeper non-desmoplastic melanomas to show stronger and more diffuse positivity than those with $<1 \mathrm{~mm}$ of invasion. 


\subsection{IMP3 expression pattern in metastatic melanoma and intranodal nevi}

Depending on the Breslow depth of a primary melanoma, sentinel lymph node biopsy is often performed for clinical staging and prognosis. In pathology departments and dermatopathology practice groups, it is not uncommon to stain sections of these sentinel nodes with various melanocytic markers in order to pick up metastatic melanoma cells. When benign, intranodal nevi occur in these specimens, the melanocytic markers will pick them up and can make diagnosis difficult if only a few cells are present. Although the clinical applicability of detecting these so-called micrometastases is debatable, accurate diagnosis is critical. As such, another study by our group was performed to see if IMP3 retained its ability to distinguish melanoma from benign nevi; and this time metastatic melanoma was compared to intranodal nevi (Mentrikoski, Ma et al. 2009).

A total 43 sentinel lymph node specimens were examined, including 30 with metastatic melanoma and 13 with intranodal nevi. The benign nevi were located both in the capsule $(n=11)$ and trabeculae $(n=2)$ (Figure 3). Melan-A was used as a general melanocytic marker, and both intranodal nevi and metastatic melanoma showed Melan-A diffuse and strong positivity (Figure 3C and 4C).
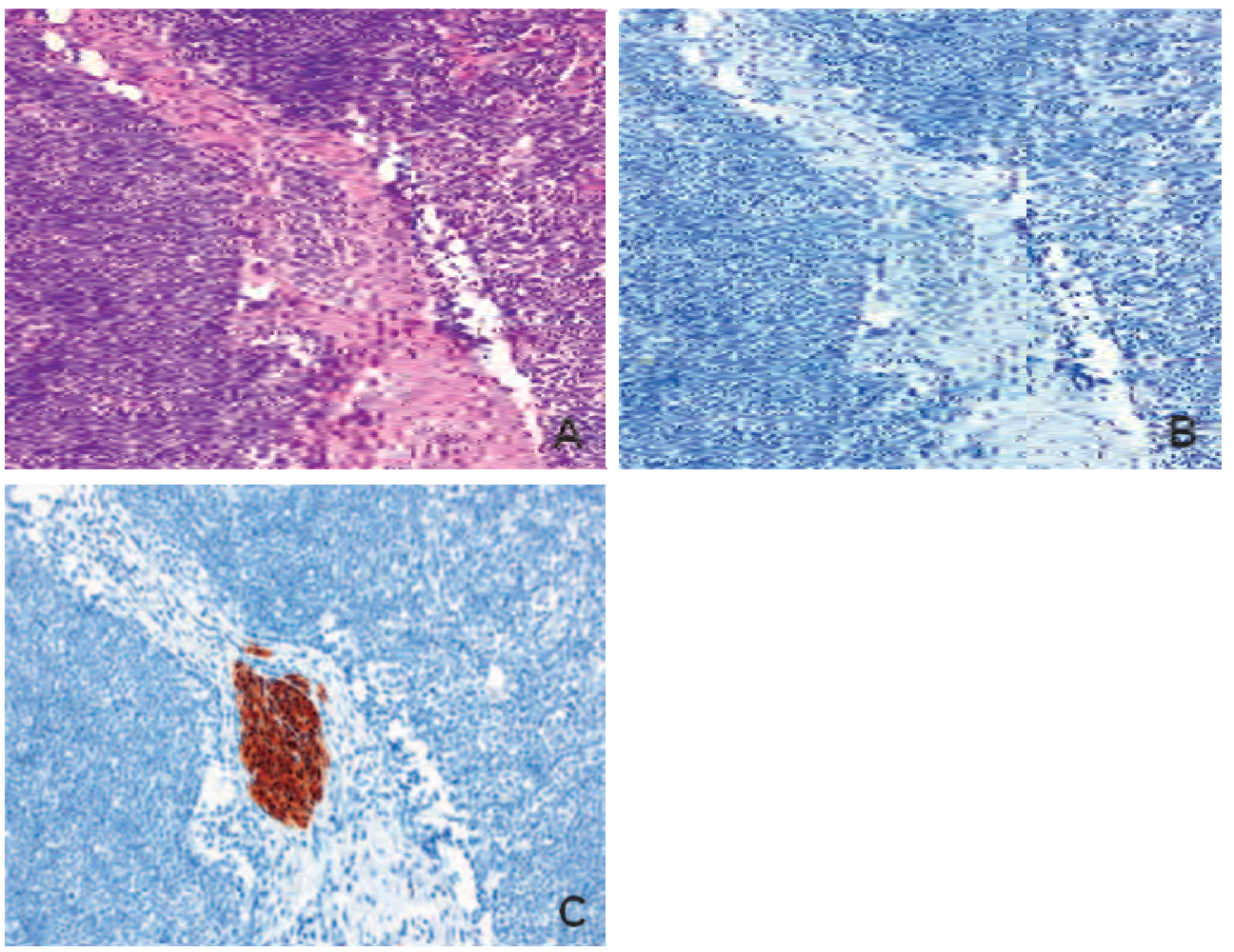

Fig. 3. Intranodal nevus is negative for IMP3. A: Hematoxylin and eosin staining shows a collection of small nevus in the trabeculae in the lymph node. B: IMP3 staining is negative in the benign nevi. C: The intranodal nevus is highlighted by Melan-A staining. Original magnification is $400 \mathrm{x}$ for $\mathrm{A}, \mathrm{B}$ and $\mathrm{C}$. 
A diagnosis of melanoma was then made based on usual cytologic features. Examination of the same lymph nodes with immunohistochemistry for IMP3 revealed expression in 21 of 30 metastatic foci $(70 \%)$ (Figure $4 \mathrm{~B}$ ) while no intranodal nevi showed positive staining (Figure 3B).
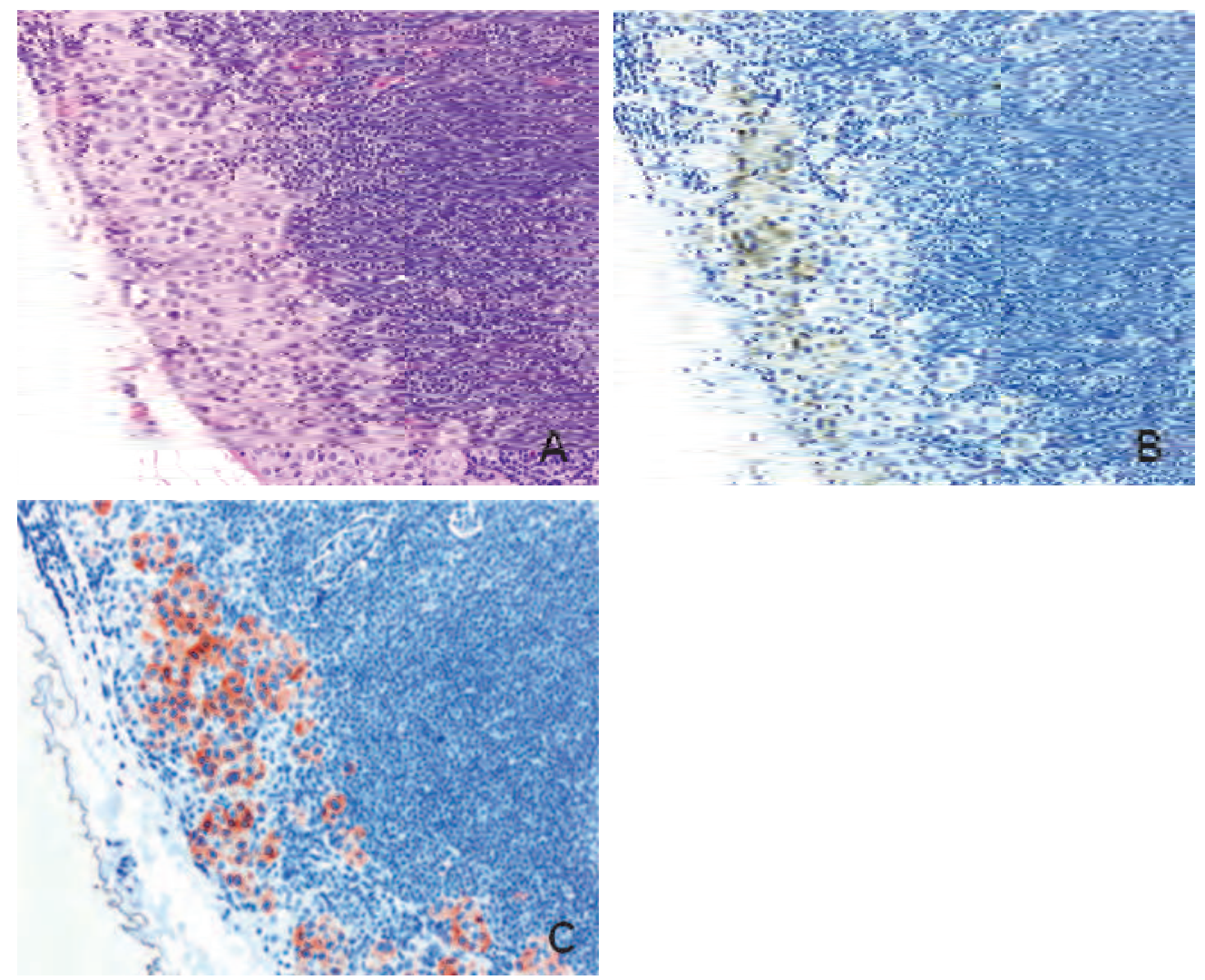

Fig. 4. Subcapsular deposit of metastatic melanoma is positive for IMP3. A: Hematoxylin and eosin staining shows a collection of malignant melanocytes within subcapsular area of the lymph node. B: Metastatic melanoma is positive for IMP3. C: Metastatic melanoma is highlighted by Melan-A staining. Original magnification are 400x for A, B and C.

The overall specificity and sensitivity in this study was comparable to the two previous cutaneous studies, and suggests that IMP3 has diagnostic utility in segregating benign nodal nevi from metastatic melanoma.

\subsection{Comparing IMP3 to other common melanocytic markers}

In general, the diagnosis of both cutaneous and metastatic melanoma can often be done on hematoxylin \& eosin stained sections alone. However, there are many times when special and immunohistochemical stains are needed to aid in proper classification; IMP3 is just one of numerous such stains that can be used. 
Although particular preference often varies amongst pathologists, and can be institutionaldependent, the immunohistochemical stains commonly used in the evaluation of questionable cases include S-100, HMB-45, and/or Melan-A. S-100 is considered the most sensitive marker (Nakajima, Watanabe et al. 1982; Ohsie, Sarantopoulos et al. 2008), but it is rather nonspecific; showing positivity in benign melanocytes, melanin-laden macrophages, dendritic cells, nerves, and adipose tissue. Both Melan-A (as used in our studies) and HMB45 show increased specificities for melanocytes when compared to S-100, but with a loss of sensitivity in melanoma cases (Ohsie, Sarantopoulos et al. 2008). With regard to lymph node metastases, one study showed HMB-45 may be more helpful than S-100 or Melan-A, as it was typically negative in most benign nevic cell rests within sentinel lymph nodes (Lohmann, Iversen et al. 2002); yet, it should be noted that HMB-45 can still be positive in up to $16 \%$ of these cases, potentially leading to false positive results. (Abrahamsen, Hamilton-Dutoit et al. 2004).

Overall, it is evident that while there is not an exceedingly high sensitivity with IMP3, the specificity is such that it is able to discriminate between benign nevi and malignant melanocytes, in both cutaneous and metastatic lesions. Like some of the other immunohistochemical stains, specifically Melan-A and HMB-45, IMP3 is hurt by its low sensitivity. Therefore, although positive immunohistochemical staining with IMP3 can increase a pathologist's confidence in the proper diagnosis of malignant melanoma, one needs to be aware of false negative results. The sensitivity and specificity of IMP3 immunohistochemical staining in malignant melanoma are summarized in table 1.

\begin{tabular}{|c|c|c|}
\hline Study & Sensitivity & Specificity \\
\hline Pryor J. G. et al. & $85 \%$ & $100 \%$ \\
\hline Yu L. et al. & $50 \%^{1}$ & $100 \%^{2}$ \\
\hline Mentrikoski M. J. et al. & $70 \%^{3}$ & $100 \% 3$ \\
\hline
\end{tabular}

Note: ${ }^{1}$ Percentage includes only non-desmoplastic melanoma; ${ }^{2}$ percentage does not include staining in both Spitz or so-called atypical Spitz nevi; ${ }^{3}$ percentage includes metastatic melanoma in lymph nodes.

Table 1. Combined sensitivity and specificity of IMP3 immunohistochemical staining for the diagnosis of malignant melanoma versus benign or dysplastic nevi.

\section{Conclusions}

Although the histopathologic diagnosis of malignant melanoma can be straightforward, many borderline cases exist where objective means to determine the proper diagnosis are largely suspected. To date, no biomarker has been found with high specificity and sensitivity for distinguishing benign from malignant melanocytic proliferations. IMP3 immunohistochemical staining has been shown to have a high specificity for identifying malignant melanoma, and with its overall sensitivity of $70 \%$, a positive immunohistochemical result can give the pathologist confidence when making a diagnosis of malignancy. In addition, IMP3 can also aid in sentinel lymph node biopsy interpretation when the differential is melanoma micrometastasis versus intranodal nevus. Future studies utilizing long-term clinical data will be needed to see if the trend of stronger IMP3 staining 
in deeper, more advanced lesions correlates with poorer patient prognosis; and ultimately a more aggressive tumor phenotype.

\section{References}

Abrahamsen, H. N., S. J. Hamilton-Dutoit, et al. (2004). "Sentinel lymph nodes in malignant melanoma: extended histopathologic evaluation improves diagnostic precision." Cancer 100(8): 1683-91.

Asioli, S., L. A. Erickson, et al. "Poorly differentiated carcinoma of the thyroid: validation of the Turin proposal and analysis of IMP3 expression." Mod Pathol 23(9): 1269-78.

Busam, K. J. (2005). "Cutaneous desmoplastic melanoma." Adv Anat Pathol 12(2): 92-102.

Do, S. I., Y. W. Kim, et al. (2008). "Expression of insulin-like growth factor-II mRNA binding protein 3 (IMP3) in osteosarcoma." Oncol Res 17(6): 269-72.

Findeis-Hosey, J. J., Q. Yang, et al. "IMP3 expression is correlated with histologic grade of lung adenocarcinoma." Hum Pathol 41(4): 477-84.

Hammer, N. A., T. O. Hansen, et al. (2005). "Expression of IGF-II mRNA-binding proteins (IMPs) in gonads and testicular cancer." Reproduction 130(2): 203-12.

Hoffmann, N. E., Y. Sheinin, et al. (2008). "External validation of IMP3 expression as an independent prognostic marker for metastatic progression and death for patients with clear cell renal cell carcinoma." Cancer 112(7): 1471-9.

Jeng, Y. M., C. C. Chang, et al. (2008). "RNA-binding protein insulin-like growth factor II mRNA-binding protein 3 expression promotes tumor invasion and predicts early recurrence and poor prognosis in hepatocellular carcinoma." Hepatology 48(4): 1118-27.

Jeng, Y. M., T. H. Wang, et al. (2009). "Prognostic significance of insulin-like growth factor II mRNA-binding protein 3 expression in gastric adenocarcinoma." Br J Surg 96(1): 66-73.

Jiang, Z. (2007). "Prognostic biomarkers in renal cell carcinoma." Expert Rev Mol Diagn 7(3): 293-307.

Jiang, Z., P. G. Chu, et al. (2006). "Analysis of RNA-binding protein IMP3 to predict metastasis and prognosis of renal-cell carcinoma: a retrospective study." Lancet Oncol 7(7): 556-64.

Jin, L., A. R. Seys, et al. "Diagnostic utility of IMP3 expression in thyroid neoplasms: a quantitative RT-PCR study." Diagn Mol Pathol 19(2): 63-9.

King, R. L., T. Pasha, et al. (2009). "IMP-3 is differentially expressed in normal and neoplastic lymphoid tissue." Hum Pathol 40(12): 1699-705.

Kobel, M., H. Xu, et al. (2009). "IGF2BP3 (IMP3) expression is a marker of unfavorable prognosis in ovarian carcinoma of clear cell subtype." Mod Pathol 22(3): 469-75.

Li, C., K. L. Rock, et al. (2007). "IMP3 is a novel biomarker for adenocarcinoma in situ of the uterine cervix: an immunohistochemical study in comparison with p16(INK4a) expression." Mod Pathol 20(2): 242-7.

Li, D., D. Yan, et al. (2009). "IMP3 is a novel prognostic marker that correlates with colon cancer progression and pathogenesis." Ann Surg Oncol 16(12): 3499-506.

Li, K. H., Y. P. Huang, et al. (2009). "[Expression of IMP3 in osteosarcoma and its clinical significance]." Xi Bao Yu Fen Zi Mian Yi Xue Za Zhi 25(5): 426-7.

Li, L., H. Xu, et al. (2008). "Expression of RNA-binding protein IMP3 (KOC) in benign urothelium and urothelial tumors." Hum Pathol 39(8): 1205-11. 
Lohmann, C. M., K. Iversen, et al. (2002). "Expression of melanocyte differentiation antigens and ki-67 in nodal nevi and comparison of ki-67 expression with metastatic melanoma." Am J Surg Pathol 26(10): 1351-7.

Lu, D., P. Vohra, et al. (2009). "An oncofetal protein IMP3: a new molecular marker for the detection of esophageal adenocarcinoma and high-grade dysplasia." Am J Surg Pathol 33(4): 521-5.

Mentrikoski, M. J., L. Ma, et al. (2009). "Diagnostic utility of IMP3 in segregating metastatic melanoma from benign nevi in lymph nodes." Mod Pathol 22(12): 1582-7.

Mueller-Pillasch, F., U. Lacher, et al. (1997). "Cloning of a gene highly overexpressed in cancer coding for a novel KH-domain containing protein." Oncogene 14(22): 272933.

Mueller-Pillasch, F., B. Pohl, et al. (1999). "Expression of the highly conserved RNA binding protein KOC in embryogenesis." Mech Dev 88(1): 95-9.

Nakajima, T., S. Watanabe, et al. (1982). "Immunohistochemical demonstration of S100 protein in malignant melanoma and pigmented nevus, and its diagnostic application." Cancer 50(5): 912-8.

Nielsen, F. C., J. Nielsen, et al. (2001). "A family of IGF-II mRNA binding proteins (IMP) involved in RNA trafficking." Scand J Clin Lab Invest Suppl 234: 93-9.

Nielsen, J., J. Christiansen, et al. (1999). "A family of insulin-like growth factor II mRNAbinding proteins represses translation in late development." Mol Cell Biol 19(2): 1262-70.

Ohsie, S. J., G. P. Sarantopoulos, et al. (2008). "Immunohistochemical characteristics of melanoma." J Cutan Pathol 35(5): 433-44.

Pryor, J. G., P. A. Bourne, et al. (2008). "IMP-3 is a novel progression marker in malignant melanoma." Mod Pathol 21(4): 431-7.

Pryor, J. G., R. A. Simon, et al. (2009). "Merkel cell carcinoma expresses K homology domaincontaining protein overexpressed in cancer similar to other high-grade neuroendocrine carcinomas." Hum Pathol 40(2): 238-43.

Righi, A., S. Zhang, et al. "Analysis of IMP3 expression in normal and neoplastic human pituitary tissues." Endocr Pathol 21(1): 25-31.

Simon, R., P. A. Bourne, et al. (2007). "Extrapulmonary small cell carcinomas express K homology domain containing protein overexpressed in cancer, but carcinoid tumors do not." Hum Pathol 38(8): 1178-83.

Slosar, M., P. Vohra, et al. (2009). "Insulin-like growth factor mRNA binding protein 3 (IMP3) is differentially expressed in benign and malignant follicular patterned thyroid tumors." Endocr Pathol 20(3): 149-57.

Thomas, A. J. and C. A. Erickson (2008). "The making of a melanocyte: the specification of melanoblasts from the neural crest." Pigment Cell Melanoma Res 21(6): 598-610.

Vikesaa, J., T. V. Hansen, et al. (2006). "RNA-binding IMPs promote cell adhesion and invadopodia formation." EMBO J 25(7): 1456-68.

Walter, O., M. Prasad, et al. (2009). "IMP3 is a novel biomarker for triple negative invasive mammary carcinoma associated with a more aggressive phenotype." Hum Pathol 40(11): 1528-33.

Wang, T., L. Fan, et al. (2003). "L523S, an RNA-binding protein as a potential therapeutic target for lung cancer." Br J Cancer 88(6): 887-94. 
Xu, H., P. A. Bourne, et al. (2007). "High-grade neuroendocrine carcinomas of the lung express $\mathrm{K}$ homology domain containing protein overexpressed in cancer but carcinoid tumors do not." Hum Pathol 38(4): 555-63.

Yaniv, K. and J. K. Yisraeli (2002). "The involvement of a conserved family of RNA binding proteins in embryonic development and carcinogenesis." Gene 287(1-2): 49-54.

Yu, L., H. Xu, et al. "IMP-3 expression in melanocytic lesions." J Cutan Pathol 37(3): 316-22.

Yuan, R. H., C. C. Wang, et al. (2009). "Diffuse expression of RNA-binding protein IMP3 predicts high-stage lymph node metastasis and poor prognosis in colorectal adenocarcinoma." Ann Surg Oncol 16(6): 1711-9.

Zheng, W., X. Yi, et al. (2008). "The oncofetal protein IMP3: a novel biomarker for endometrial serous carcinoma." Am J Surg Pathol 32(2): 304-15. 


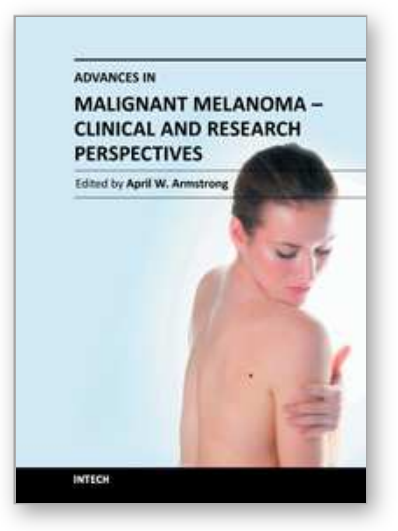

\author{
Advances in Malignant Melanoma - Clinical and Research \\ Perspectives \\ Edited by Dr. April Armstrong
}

ISBN 978-953-307-575-4

Hard cover, 252 pages

Publisher InTech

Published online 22, September, 2011

Published in print edition September, 2011

This book titled Advances in Malignant Melanoma - Clinical and Research Perspectives represents an international effort to highlight advances in our understanding of malignant melanoma from both clinical and research perspectives. The authors for this book consist of an international group of recognized leaders in melanoma research and patient care, and they share their unique perspectives regarding melanoma epidemiology, risk factors, diagnostic and prognostic tools, phenotypes, treatment, and future research directions. The book is divide into four sections: (1) Epidemiology and Risk Factors of Melanoma, (2) Clinical Phenotypes of Melanoma, (3) Investigational Treatments for Melanoma and Pigmentary Disorders, and (4) Advances in Melanoma Translational Research. This book does not attempt to exhaustively cover all aspects of the aforementioned topics. Rather, it is a compilation of our authorsâ $€^{\mathrm{TM}}$ pearls and unique perspectives on the relevant advances in melanoma during the recent years.

\title{
How to reference
}

In order to correctly reference this scholarly work, feel free to copy and paste the following:

Mark J. Mentrikoski and Haodong Xu (2011). IMP3 and Malignant Melanoma, Advances in Malignant Melanoma - Clinical and Research Perspectives, Dr. April Armstrong (Ed.), ISBN: 978-953-307-575-4, InTech, Available from: http://www.intechopen.com/books/advances-in-malignant-melanoma-clinical-and-researchperspectives/imp3-and-malignant-melanoma

\section{INTECH}

open science | open minds

\section{InTech Europe}

University Campus STeP Ri

Slavka Krautzeka 83/A

51000 Rijeka, Croatia

Phone: +385 (51) 770447

Fax: +385 (51) 686166

www.intechopen.com

\section{InTech China}

Unit 405, Office Block, Hotel Equatorial Shanghai

No.65, Yan An Road (West), Shanghai, 200040, China

中国上海市延安西路65号上海国际贵都大饭店办公楼 405 单元

Phone: +86-21-62489820

Fax: $+86-21-62489821$ 
(C) 2011 The Author(s). Licensee IntechOpen. This chapter is distributed under the terms of the Creative Commons Attribution-NonCommercialShareAlike-3.0 License, which permits use, distribution and reproduction for non-commercial purposes, provided the original is properly cited and derivative works building on this content are distributed under the same license. 